Academic Platform Journal of Engineering and Science

journal homepage: http://apjes.com/

\title{
Hayvansal Atık Kaynakı Biyogaz Potansiyeli: Bitlis Örneği
}

\author{
${ }^{1 *}$ Ayşegül Demir Yetiş, ${ }^{1}$ Leyla Gazigil, ${ }^{2}$ Recep Yetiş, ${ }^{3}$ Burçin Çelikezen
}

${ }^{1}$ Bitlis Eren Üniv., Müh.- Mim. Fak., Çevre Müh. Böl. Bitlis, ademir@beu.edu.tr, ${ }^{1}$ Bitlis Eren Üniv., Müh.- Mim. Fak., Çevre Müh. Böl. Bitlis, leylagazigil@ hotmail.com, ${ }^{2}$ Bitlis Eren Üniv., Sağlık Hizmetleri MYO, Çevre Sağlığı Prog., Bitlis, ryetis@beu.edu.tr,

${ }^{3}$ Bitlis İl Tarım ve Orman Müdürlüğ̈̈, Bitlis, burcinozer44@gmail.com,

\section{$\ddot{O} \mathbf{z}$}

\begin{abstract}
Bu çalışmada, Bitlis ilinin ve ilçelerinin hayvan sayısından oluşan atık miktarlarından biyogaza dönüştürülme potansiyeli ele alınarak oluşabilecek enerji miktarı ve yakıt tasarruf miktarları belirlenmiştir. 2017 yılına ait Bitlis il geneli için büyükbaş, küçükbaş ve kanatlı (tavuk) hayvan sayısı sırasıyla 82406, 601555 ve 78424 adettir. Bu hayvanlardan oluşan atık miktarları hesaplandıktan sonra Agro-Waste projesi kapsamında belirtilen oranlar ile kullanılabilir atık miktarı büyükbaş için 532425,166 (ton/yıl), küçükbaş için 64125,763 (ton/yıl) ve kanatlı (tavuk) için 2251,553 (ton/yll) olarak elde edilmiştir. Biyogaza karşıllk gelen değerler ise her biri için 17570030,48 m³/y1l, 3719294,25 m²/y1 ve 175621,13 m³/y1 olarak hesaplanmıştır. Sonuç olarak büyükbaş hayvan sayısının fazla, toplam hayvan sayısının az olduğu Güroymak ilçesi 5,3 milyon $\mathrm{m}^{3} / \mathrm{y} 1 \mathrm{l}$ miktarla biyogaz potansiyelinin en yüksek olduğu ilçedir. Ayrıca Bitlis iline ait toplam biyogaz potansiyeli yaklaşık 21,46 milyon $\mathrm{m}^{3} / \mathrm{yll}$ olarak tespit edilmiştir.
\end{abstract}

Anahtar Kelimeler: Bitlis, Hayvansal atık, Biyogaz üretimi, Enerji potansiyeli

\section{Biogas Potential from Animal Waste: A Case Study for Bitlis Province}

\author{
${ }^{1 *}$ Ayşegül Demir Yetiş, ${ }^{1}$ Leyla Gazigil, ${ }^{2}$ Recep Yetiş, ${ }^{3}$ Burçin Çelikezen \\ ${ }^{1}$ Bitlis Eren Univ., Faculty of Engineering and Architecture, Dept. of Environmental Engineering, Bitlis. \\ ademir@beu.edu.tr \\ ${ }^{1}$ Bitlis Eren Univ., Faculty of Engineering and Architecture, Dept. of Environmental Engineering. Bitlis. \\ leylagazigil@ hotmail.com \\ ${ }^{2}$ Bitlis Eren University, Bitlis Eren University Department of Environmental Health, Bitlis. \\ ryetis@beu.edu.tr \\ ${ }^{3}$ Bitlis Directorate of Provincial Agriculture and Forestry, Bitlis \\ burcinozer44@gmail.com
}

\begin{abstract}
In this study, amount of energy and amount of fuel savings that can be formed by considering the biogas conversion potential from the amount of waste of animal counts of the city of Bitlis and its counties has been determined. The number of bovine, ovine and poultry (chickens) animals belonging to the year 2017 are 82406, 601555 and 78424 for Bitlis provincial. After calculating the amount of wastes generated from these animals, the amount of waste that can be used with the rates specified in the Agro-Waste project was 532425,166 (ton / year), 64125,763 (ton / year) and 2251,553 (ton / year). Biogas response values were calculated as $17570030,48 \mathrm{~m} 3 /$ year, $3719294,25 \mathrm{~m}^{3} /$ year and $175621,13 \mathrm{~m}^{3} /$ year respectively. As a result, the Güroymak district where the number of bovine animal is high and the number of total animal is low has the highest biogas potential with the approximate 5.3 million $\mathrm{m}^{3} / \mathrm{year}$. In addition to this, the total biogas potential belonging to the Bitlis cit has been determined as 21.46 million $\mathrm{m}^{3} / \mathrm{year}$.
\end{abstract}

Keywords: Bitlis, Animals waste, Biogas production, Energy potential

*1Sorumlu Yazar: Bitlis Eren Üniversitesi, Mühendislik Fakültesi, Çevre Mühendisliği Bölümü, Rahva Kampüsü, Bitlis, ademir@beu.edu.tr, Tel: +90(434) 2220030 / D: 3212 


\section{GÍRIŞ̧}

Dünya nüfusunun zamanla büyük bir artış göstermesi, endüstriyel gelişim ve insanların yaşam standardının yükselmesi, enerjiye olan talebi ve gereksinimi gittikçe arttırmaktadır. $\mathrm{Bu}$ artışlar mevcut enerjinin bir süre sonra talebi karşılayamamasına ve sonuç olarak artan enerji ihtiyacı ve maliyeti, enerji anlamında yeni arayışlar içerisine girmemize sebep olmaktadır [1;13]. Dünyanın geleceği için enerji çok büyük bir öneme sahip olup ekonomik gelişmenin merkezidir. Bilinen enerji kaynakları; fosil yakıtlar, yenilenebilir enerji kaynakları ve nükleer enerji kaynakları olarak sıralanabilmektedir [7]. Fosil yakıtları ülkemizde olduğu gibi birçok ülkede de enerji ihtiyacının temelini oluşturmaktadır. Dünyanın bir yılda ihtiyacı olan enerji miktarının 400 EJ olduğu ve bunun da yaklaşık \%80'ninin fosil yakıttan karşılandığı düşünüldügüunde, çevre kirliliğinin boyutları çevreyi ve bütün canlıları tehdit etme aşamasına gelmiştir. Özellikle 20. yüzyılda fosil yakıtların aşırı kullanımı ile ozon tabakasında meydana gelen incelme, asit yağmurlarının daha sık görülmeye başlanması ve küresel ısınma gibi çevreye zarar veren olayların artması ve bu yakıtların tükenebilir kaynaklar olması alternatif enerjiye olan rağbeti arttırmıştır $[1 ; 15]$. Alternatif enerji kaynağ olarak doğaya zarar vermeyen ve zamanla tükenmeyen yenilenebilir enerji kaynaklarından en çok güneş ve rüzgâr enerjisi tercih edilmektedir [16]. Bunun yanında son zamanlarda hayvansal atıklardan ve çöplerden elde edilen biyogaz üretme reaktörleri önem kazanmaktadır. Günümüzde sürdürülebilir biyoenerji üretiminin artması sayesinde fosil yakıtlardan kaynaklanan çevre kirliliği azalmış olacaktır [10].

Yenilenebilir enerji kaynaklarından biyogaz enerjisinin çevre dostu olması ve maliyet açısından ekonomik olması günden güne önemini arttırmıştır [1;9]. Biyogaz üretimi atık yönetimi açısından; organik atıkların kullanılması, atık bertarafi ve atıklardan enerji elde edilmesi yönünden etkin bir adım olarak karşımıza çıkmaktadır [13]. Birçok ülkede biyokütlenin biyogaza dönüştürülmesi, sürdürülebilir kalkınmaya katkının yanında enerji tasarrufunu sağlar ve sera gazı yayılımlarını azaltır [12]. Biyogaz; orman ürünleri, evsel ve endüstriyel atıklar, tarımsal atıklar ve hayvan gübresi gibi birçok organik atıktan oluşmuş yanıcı bir gaz karışımı olup, dönüştürülmüş enerji olarak tanımlanır [4]. Biyogaz, organik maddelerin mikroorganizma varlığında oksijensiz ortamda, metalaştırma süreci ile oluşmakta ve içeriğinde metan $\left(\mathrm{CH}_{4}\right)$, karbondioksit $\left(\mathrm{CO}_{2}\right)$, azot $\left(\mathrm{N}_{2}\right)$, hidrojen sülfür $\left(\mathrm{H}_{2} \mathrm{~S}\right)$, amonyak $\left(\mathrm{NH}_{3}\right)$, hidrojen $\left(\mathrm{H}_{2}\right)$ ve karbonmonoksit (CO) bulunmaktadır [2]. Biyogaz üretiminin verimi; $\mathrm{pH}, \quad$ sıcaklık, karıştırma gibi parametrelerin uygun olmasına bağlıdır.

Ülkemiz hayvansal ve bitkisel üretim açısından yüksek bir potansiyele sahip ancak bu atıklar biyogaz üretiminde değerlendirilemeyerek, ya tarım topraklarında gübre olarak kullanılmakta veya doğrudan doğruya yakılmaktadır. Biyogazdan enerji üretimi 1980'den önce başlamış, 2000 yılında önemi anlaşılmış ve çalışmalar hız kazanmıştır.
Biyogaz çalışmaları ilk olarak tavuk çiftliklerinde 2004 yılında denenmiş ardından küçükbaş ve büyükbaş çiftliklerinde de çalışmalara devam edilmiştir. Nihai olarak biyogaz üretim tesislerinin birçoğu 2005 yılı itibariyle kurulmuştur [13]. Bu tesislerin kurulması; kırsal kesimlerde ve köylerde hayvansal atıkların daha sağlıklı bir şekilde değerlendirilmesini sağlamıştır. Ayrıca yemek pişirme, 1sınma, aydınlanma gibi alanlarda elde edilen enerji kullanılarak ekonomiye katkı sağlanmıştır [14].

Bu çalışmada; Bitlis ilindeki toplam hayvan sayısına göre 2017 yılı için biyogaz, enerji potansiyeli ve yakıt tasarrufu hesabı yapılmıştır.

\section{MATERYAL VE YÖNTEM}

\section{1. Çalıșma Alanı}

Bitlis ili, Türkiye'nin Doğu Anadolu Bölgesinde yer almakta olup, yüzölçümü 8.855 km2'lik bir alana sahiptir. İl 7 ilçeden oluşmakta, bunlardan Adilcevaz, Ahlat ve Tatvan ilçelerinin Van Gölü ile sınırı bulunmaktadır (Şekil 1) [3]. Genel olarak karasal iklim özellikler göstermesine rağmen, gerçekte doğunun sert karasal iklimiyle Akdeniz iklimi arasında bir geçiş niteliği taşımaktadır. Kışlar soğuk ve kar yağışlı, yazlar ise kurak geçmektedir. Temel geçim kaynağı tarım ve hayvancılıktır. Karasal iklime sahip olan ilde zirai faaliyetler arasında önemli yeri hayvancılık almaktadır [6]

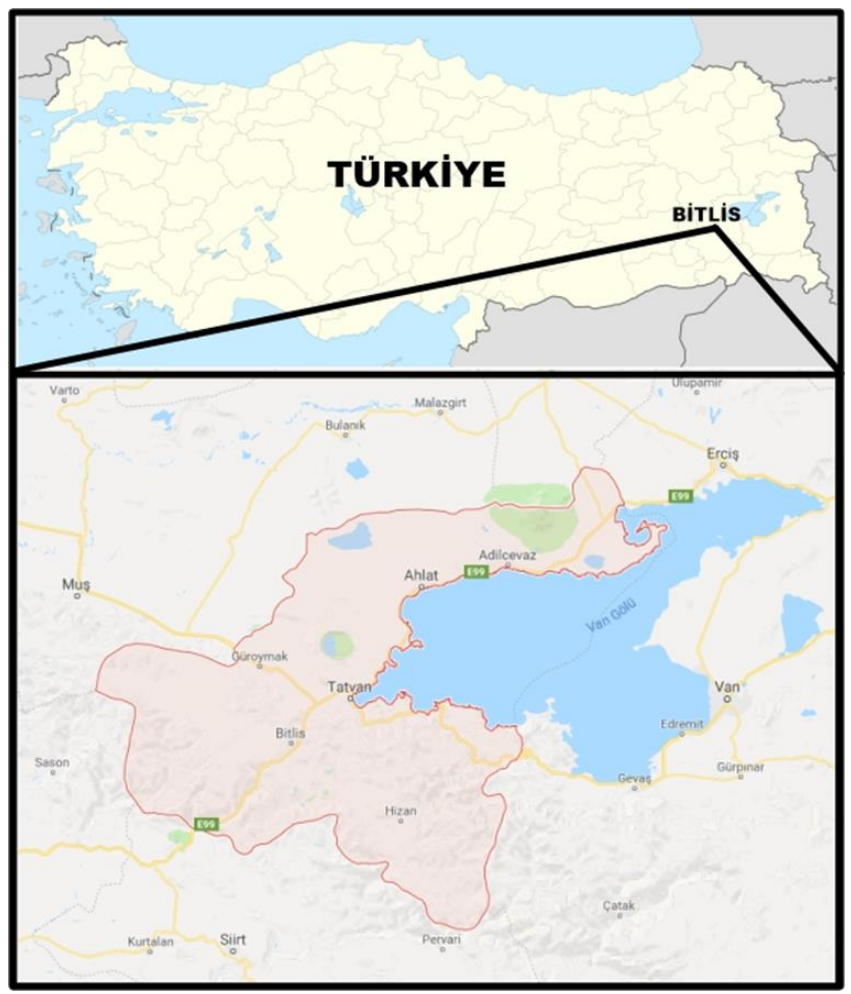

Şekil 1. Bitlis İli ve İlçeleri 


\subsection{Yöntem}

Çalışma kapsamında incelen Bitlis ilinin hayvan sayısı Bitlis İl Gıda Tarım ve Hayvancılık Müdürlüğü'nden alınmıștır. Hayvan sayıs1 verileri 31.12.2017 tarihine ait olup Bitlis Merkez ve ilçelerini kapsamaktadır. Çalışma üç aşamalı olup, birinci aşamada ilgili hayvan atığının belirlenmesi ve atık miktarının hesaplanması, ikinci aşamada kullanılabilir atık miktarlarının hesaplanması, üçüncü aşamada ortaya çıkan kullanılabilir atık miktarından meydana gelebilecek biyogaz miktarlarının hesaplaması yapılmıştır. Ayrıca biyogaz potansiyelini belirlemek için aşağıdaki kabuller ve araştırma sonuçları kullanılmıştır. Bunlara göre Bitlis ilindeki 2017 yılında toplam hayvan sayısından; gübre, biyogaz ve enerji potansiyeli hesabı yapılmıştır.

\section{Gübre ile ilgili kabuller (Agro-Waste)}

Büyükbaş hayvandan 9,94 ton/yıl, küçükbaş hayvandan 0,82 ton/yıl, kanatlı (tavuk) hayvandan 0,029 ton/yıl gübre ortalama olarak elde edildiği kabul edilir. Gübrelerin yaklaşık olarak büyükbaş hayvan için \% 65, Küçükbaş için \% 13 ve kümes hayvanları için \% 99'u hesaba katılarak diğer kısmın meralarda kaybolduğu dikkate alınmıştır $[1,2,17,18]$.

\section{Biyogaz ile ilgili kabuller (Agro-Waste)}

1 ton büyükbaş hayvan gübresinden $33 \mathrm{~m}^{3}$ biyogaz, 1 ton küçükbaş hayvan gübresinden $58 \mathrm{~m}^{3}$ biyogaz, 1 ton kanatlı (tavuk) hayvan gübresinden $78 \mathrm{~m}^{3}$ biyogaz elde edildiği dikkate alınmıştır $[1,2,17,18]$.

Biyogazın elektrik enerjisi ve diğer yakıtların eşdeğeri olarak yapılan kabuller

$1 \mathrm{~m}^{3}$ biyogazın sağladığı 1S1 miktarı; 0,63 L gaz yağına, 3,47 $\mathrm{kg}$ oduna, $0,43 \mathrm{~kg}$ bütan gazına, $4,7 \mathrm{kWh}$ elektriğe ve $0,8 \mathrm{~L}$ benzine eş değerdir $[1,2,17,18]$.

\section{BULGULAR VE TARTIŞMA}

Bitlis ve ilçelerinde halkın önemli geçim kaynağı hayvancılıktır. Büyük çoğunluk mera hayvancılığı üzerine olup, küçükbaş hayvan yetiştiriciliği daha yüksek bir orana sahiptir. İlin büyükbaş, küçükbaş ve kanatlı (tavuk) hayvan sayılarının ilçelere göre dağılımı Tablo 1'de sunulmuştur. Buna göre il geneline baktığımızda; en fazla büyükbaş hayvan sayısı Güroymak, en fazla küçükbaş hayvan sayısı Tatvan ve en fazla kanatlı (tavuk) sayısı Adilcevaz ilçelerinde bulunmaktadır. En az büyükbaş hayvan sayısı Adilcevaz, en az küçükbaş hayvan sayısı Bitlis Merkez ve en az kanatlı sayısı Tatvan ilçelerindedir.
Tablo 1. Bitlis Merkez ve İlçeleri bazında hayvan sayısı (31.12.2017)

\begin{tabular}{|l|l|l|l|}
\hline Cins (Adet) & Büyükbaş & Küçükbaş & Kanatlı \\
\hline Merkez & 6246 & 50603 & 10648 \\
\hline Adilcevaz & 4677 & 105503 & 18500 \\
\hline Ahlat & 11874 & 85410 & 8882 \\
\hline Güroymak & 23412 & 60713 & 11002 \\
\hline Hizan & 7137 & 65425 & 9500 \\
\hline Mutki & 17571 & 115575 & 12892 \\
\hline Tatvan & 11489 & 118326 & 7000 \\
\hline Toplam & 82406 & 601555 & 78424 \\
\hline
\end{tabular}

Bu çalışmada Bitlis ilindeki hayvan sayıları göz önünde bulundurulup hayvansal atık potansiyeli ve kullanılabilen miktarlar hesaplanmıştır (Tablo 2). Kullanılabilen atık miktarı toplamda 598802,482 ton/y1l olarak tespit edilmiştir.

Tablo 2. Toplam atık ve kullanılabilir atık miktarları

\begin{tabular}{|c|r|r|r|}
\hline Cins & \multicolumn{1}{|c|}{ Büyükbaş } & \multicolumn{1}{|c|}{ Küçükbaş } & \multicolumn{1}{l|}{ Kanatlı } \\
\hline Hayvan Sayısı & 82406 & 601555 & 78424 \\
\hline Kabul (ton/yıl) & 9,94 & 0,82 & 0,03 \\
\hline $\begin{array}{c}\text { Toplam Atık } \\
\text { (ton/yıl) }\end{array}$ & 819115,64 & 493275,1 & 2274,296 \\
\hline $\begin{array}{c}\text { Kullanılabilen } \\
\text { Atık (ton/yıl) }\end{array}$ & 532425,17 & 64125,763 & 2251,553 \\
\hline
\end{tabular}

Kullanılabilir atık miktarına göre biyogaz potansiyeline ait grafik Şekil 2'de verilmiştir. Buna göre Bitlis Merkez ve ilçelerinin hayvancılıktan elde edilebilecek biyogaz potansiyelinin \%82'sini büyükbaş, \%17'sini küçükbaş ve \%1'lik kısmını kanatlı hayvan oluşturmaktadır. İlçeler bazında değerlendirildiğinde büyükbaş hayvandan elde edilen y1llık biyogaz potansiyelinin en fazla olduğu ilçe Güroymak, en az olduğu ilçe Adilcevaz'dır. Küçükbaş hayvandan elde edilen yillık biyogaz potansiyelinin en fazla olduğu ilçe Tatvan, en az olduğu ilçe Merkezdir. Kanatlı hayvandan elde edilen yıllık biyogaz potansiyeli yaklaşık olarak birbirine yakın olmakla birlikte düşük bir orana sahiptir (Şekil 3).

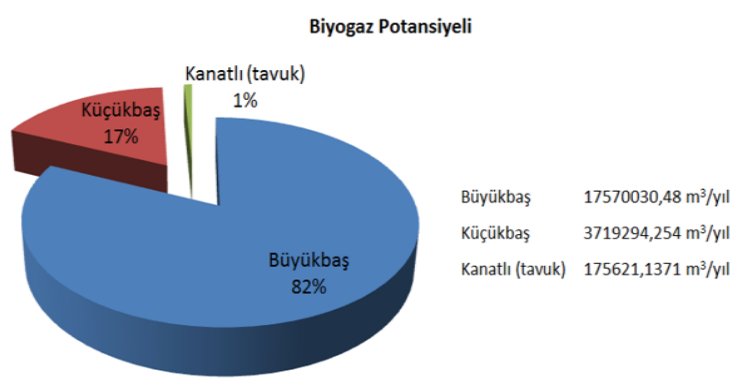

Şekil 2. Hayvancılıktan elde edilebilecek toplam gaz miktarı 


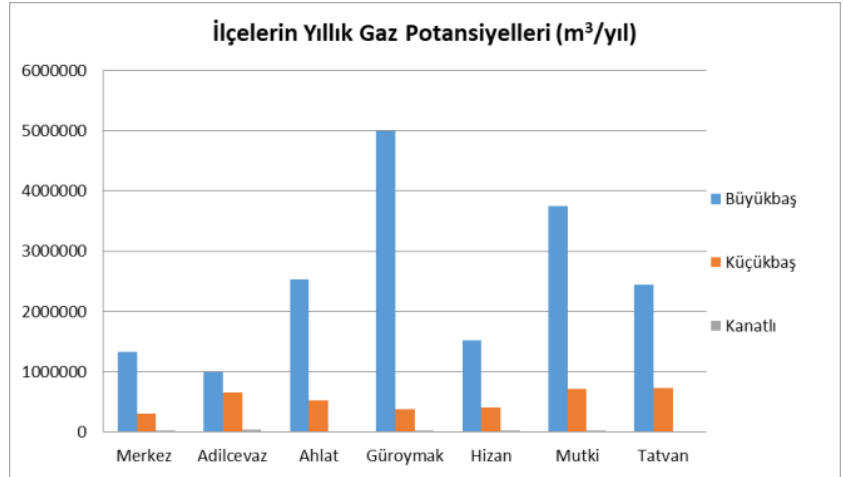

Şekil 3. İlçelere ve hayvan dağılımlarına göre gaz potansiyelleri

$1 \mathrm{~m}^{3}$ biyogazdan $5000 \mathrm{kcal}$ enerji elde edilmekte olup; diğer yakıtlarla karşılaştırıldığında 4,70 kWh elektrik, 0,62 L gazyağ1, 3,47 kg odun, 1,46 kg kömür, 1,18 $\mathrm{m}^{3}$ doğalgaz ile eşdeğerdir [5]. Toplam biyogaz miktarının diğer yakıtlardaki karşılığı Tablo 3'de verilmiş olup, buna göre biyogaz miktarının ve yakıt çeşidinin en fazla olduğu ilçe Güroymak'tır.

Tablo 3. Toplam biyogaz miktarının diğer yakıtlardaki karşılığ1

\begin{tabular}{|c|c|c|c|}
\hline Yakıt çeşidi & $\begin{array}{c}\text { Biyogaz } \\
\left(\mathrm{m}^{3}\right)\end{array}$ & $\begin{array}{c}\text { Elektrik } \\
(\mathbf{k W h})\end{array}$ & $\begin{array}{c}\text { Gazyağı } \\
\text { (L) }\end{array}$ \\
\hline Merkez & 1668442 & 7841675 & 1034434 \\
\hline Adilcevaz & 1690930 & 7947369 & 1048376 \\
\hline Ahlat & 3079654 & 14474375 & 1909386 \\
\hline Güroymak & 5391757 & 25341257 & 3342889 \\
\hline Hizan & 1947485 & 9153179 & 1207441 \\
\hline Mutki & 4489813 & 21102120 & 2783684 \\
\hline Tatvan & 3196866 & 15025269 & 1982057 \\
\hline TOPLAM & 21464946 & 100885246 & 13308266 \\
\hline Yakıt çeşidi & $\begin{array}{c}\text { Odun } \\
(\mathrm{kg})\end{array}$ & $\begin{array}{c}\text { Kömür } \\
\text { (kg) }\end{array}$ & $\begin{array}{c}\text { Doğalgaz } \\
\left(\mathrm{m}^{3}\right)\end{array}$ \\
\hline Merkez & 5789492 & 2435925 & 1968761 \\
\hline Adilcevaz & 5867526 & 2468757 & 1995297 \\
\hline Ahlat & 10686400 & 4496295 & 3633992 \\
\hline Güroymak & 18709396 & 7871965 & 6362273 \\
\hline Hizan & 6757773 & 2843328 & 2298032 \\
\hline Mutki & 15579650 & 6555127 & 5297979 \\
\hline Tatvan & 11093124 & 4667424 & 3772302 \\
\hline TOPLAM & 74483362 & 31338821 & 25328636 \\
\hline
\end{tabular}

2017 yılına ait hayvan sayısına bağlı olarak yıllık üretilebilen 21,46 milyon $\mathrm{m}^{3}$ biyogaz enerji eşdeğerindeki yakıt oranları belirlenerek güncel fiyatlarla hesaplanan tasarruf miktarları Tablo 4'te görülmektedir. En fazla yakıt tasarrufu yaklaşık 60 milyon TL ile gazyağı, en düşük ise yaklaşık 28 milyon TL tutarı ile kömür yakıtı olarak tespit edilmiştir.
Tablo 4. Tasarruf miktarları

\begin{tabular}{|c|c|}
\hline & $\begin{array}{l}\text { Tasarruf miktarı } \\
\text { (milyon) TL }\end{array}$ \\
\hline Elektrik (kWh) & 44,15 \\
\hline Gazyağı (L) & 59,88 \\
\hline \begin{tabular}{|l|} 
Odun (kg) \\
\end{tabular} & 37,24 \\
\hline Kömür (kg) & 27,89 \\
\hline Doğalgaz $\left(\mathrm{m}^{3}\right)$ & 28,38 \\
\hline
\end{tabular}

\section{SONUÇLAR}

$\mathrm{Bu}$ çalışmada Bitlis ilindeki toplam hayvan sayısına göre 2017 yılı için gübre, biyogaz, enerji potansiyeli ve yakıt tasarrufu hesabı yapılmıştır. Biyogaz potansiyeli büyükbaş, küçükbaş ve kanatlı hayvan (tavuk) için sırasıyla $17570030,48 \mathrm{~m}^{3} / \mathrm{y} 11,3719294,25 \mathrm{~m}^{3} / \mathrm{y} 1 \mathrm{l}$ ve $175621,13 \mathrm{~m}^{3} / \mathrm{y} 1 \mathrm{l}$ olarak hesaplanmıştır. İlin toplam biyogaz miktarı yaklaşık olarak 21,46 milyon $\mathrm{m}^{3} /$ y1l olarak elde edilmiştir. Güroymak ilçesinin toplamdaki hayvan sayısının düşük olmasına rağmen, büyükbaş hayvan sayısının fazla olmasından dolayı biyogaz potansiyeli 5,3 milyon $\mathrm{m}^{3} /$ yıl değeri ile en yüksek olduğu ilçedir. Yakıt tasarrufu bakımından yaklaşık 60 milyon TL ile gazyağı en fazla, yaklaşık 28 milyon TL tutarı ile Kömür ise en düşük yakıt olarak hesaplanmıştır. Hesaplanan toplam biyogaz enerji miktarı ile bütün ilin enerji ihtiyacını karşılamasa da mikro ölçekli bir işletme tesisinin enerji ihtiyacını karşılayarak kar elde edilebilir. $\mathrm{Bu}$ sayede dışarıdan ithal edilen enerjiye karşılık alternatif bir enerji çeşidi ortaya çıkmış ve oluşan katı atıklar güvenli bir şekilde bertaraf edilerek çevre sorunları önlenmiş olacaktır. Ayrıca 1sı üretiminden sonra kalan atık tarlalarda gübre olarak değerlendirilebilir.

\section{KAYNAKLAR}

[1].Altıkat, S. ve Çelik, A. (2012). Iğdır İlinin Hayvansal Atık Kaynaklı Biyogaz Potansiyeli Biogas Potential from Animal Waste of Iğdır Province. Iğdır Üni. Fen Bilimleri Enst. Der, 2(1), 61-66.

[2].Baran, M. F., Lüle, F. ve Gökdoğan, O. (2017). Adıyaman İlinin Hayvansal Atıklardan Elde Edilebilecek Enerji Potansiyeli Energy Potential Can Be Produced by Animal Waste of Adiyaman Province. Türk Tarım ve Doğa Bilimleri Dergisi, 4(3), 245-249.

[3].Duzen, H. ve Aydin, H. (2012). Sunshine-based estimation of global solar radiation on horizontal surface at Lake Van region (Turkey). Energy Conversion and Management, 58, 35-46. doi:10.1016/j.enconman.2011.11.028

[4].Ergür, H. S. ve Okumuş, F. (2010). Cost and Potential Analysis of Biogas in Eskisehir. Uludağ Üniversitesi Mühendislik-Mimarlık Fakültesi Dergis, 2(15), 155-160.

[5].Gümüşçü M., Uyanık S., (2010). Güneydoğu Anadolu Bölgesi Hayvansal Atıklarından Biyogaz ve Biyogübre Eldesi. Tesisat Mühendisliği (MMO), 16 (118), 59-65.

[6].IÇDR,2016.T.C Çevre ve Şehircilik Bakanlığı Bitlis İl Çevre Durum Raporu. 
[7].Karaca, C. (2017). Hatay İlinin Hayvansal Gübre Kaynağından Üretilebilir Biyogaz Potansiyelinin Belirlenmesi. Mustafa Kemal Üniversitesi Ziraat Fakültesi Dergisi YIL/YEAR, 22(1), 34-39.

[8].Karim, K., Hoffmann, R., Klasson, T.K. Al-Dahhan, M.H., 2005. Anaerobic digestion of animal waste: Effect of mode of mixing. Water Research, 39: 3597-360

[9].Kaya, D., Çankakılıç, F., Dikeç, S., Baban, A., Güneş, K., (2005). Türkiye'de tarımsal atıkların değerlendirilmesi rehberi, LIFE 03 TCY/TR/000061 proje raporu, Tubitak.

[10]. Lijó, L., González-García, S., Bacenetti, J. ve Moreira, M. T. (2016). The environmental effect of substituting energy crops for food waste as feedstock for biogas production. Energy. doi:10.1016/j.energy.2017.04.137

[11]. Namsaraev, Z. B., Gotovtsev, P. M., Komova, A. V. ve Vasilov, R. G. (2018). Current status and potential of bioenergy in the Russian Federation. Renewable and Sustainable Energy Reviews, 81, 625-634. doi:10.1016/j.rser.2017.08.045

[12]. Özer, B.(2017). Biogas energy opportunity of Ardahan city of Turkey. Energy 139 (2017) $1144 \mathrm{e} 1152$. http://dx.doi.org/10.1016/j.energy.2017.07.052

[13]. Tinmaz, K. E. (2017). Trakya bölgesinde hayvan gübrelerinin biyogaz enerji potansiyelinin belirlenmesi ve sayısal haritaların oluşturulması. Pamukkale University Journal of Engineering Sciences, 23(6), 762-772. doi:10.5505/pajes.2016.33600

[14]. Ulusoy, Y., Unal, H. ve Alibaş, K. (2009). Bursa İli Karacabey İlçesinde Örnek Bir Biyogaz Tesisinin Kurulabilirliği İçin Tar msal ve Gıda Artıklarının Enerji Potansiyeli. 25. Tarımsal Mekanizasyon Ulusal Kongresitarımsal mekanızasyon ulusal kongresi içinde (ss. 109-115). Isparta.

[15]. Yokuş, İ. ve Avcıoğlu, A. O. (2012). Sivas İlindeki Hayvansal Atıklardan Biyogaz Potansiyelinin Belirlenmesi. 27. Tarımsal Mekanizasyon Ulusal Kongresi içinde (ss. 488 498). Samsun.

[16]. Zareei, S. (2018). Evaluation of biogas potential from livestock manures and rural wastes using GIS in Iran. Renewable Energy, 118, 351-356. doi:10.1016/j.renene.2017.11.026

[17]. Kaya, D., Çağman, S., Eyidoğan, M., Aydoner, C., Çoban, V., Tırıs M. (2009) Türkiye'nin Hayvansal Atık Kaynaklı Biyogaz Potansiyeli ve Ekonomisi. Atık Teknolojileri Dergisi Sayı 1 Temmuz Ağustos 2009.

[18]. Deniz, E., Yeşilören, G., Özdemir, N., İşçi, A. (2015). Türkiye'de Gıda Endüstrisi Kaynaklı Biyokütle ve Biyoyakıt Potansiyeli. GIDA (2015) 40 (1): $47-54$ doi: $10.15237 /$ gida.GD14037 